\title{
Project NANO (Nanoscience and Nanotechnology Outreach): Portland, Oregon
}

\author{
S.L. Cady, ${ }^{*}$ M.A. Blok, ${ }^{* *}$ K.P. Grosse, ${ }^{* * *}$ W. Becker****, and C. Schooley***** \\ * Department of Geology, Portland State University, 1721 SW Broadway, 17CH, Portland, OR \\ 97201, ** Beaverton High School, Beaverton, OR, *** Lake Oswego High School, Lake Oswego, \\ OR, **** Center for Science Education, Portland State University, Portland, OR, ***** MSA \\ Project MICRO Coordinator, Caspar, CA
}

Project NANO (Nanoscience and Nanotechnology Outreach) is a Portland, Oregon, based teacher training program that brings nanoscience tools into the classrooms of highly motivated grade 7-12 teachers and gives them the skills and content knowledge needed to teach their students how to design and complete their own inquiry-based science projects. The program was designed to improve high school, college, and STEM career readiness by providing a unique hands-on program that links visually and quantitatively the conceptual relationship between structure and function, science inquiry, and engineering design - all key themes in the new State/National STEM Standards.

To date, Project NANO has tutored two cohorts (10+ each) of pre- and in-service STEM teachers to be knowledgeable and comfortable when teaching and advising nanoscience concepts with a tabletop scanning electron microscope. Each cohort of STEM teachers receives basic training in the theoretical, applied, and instructional aspects of scanning electron microscopy. Participants also acquire experience through development of guided inquiry-based SEM lesson plans that integrate directly into their existing curricula, and they learn techniques to engage as many as thirty students in STEM skills via access to optical and scanning electron microscopes in their classrooms. Longterm access to an expanding set of lesson plans, as developed and tested by other Project NANO teachers, is established as well. By training teacher cohorts in metropolitan regions such as the greater Portland metro area, a sustainable program has emerged that can be adopted by any community eager to bring nanoscience and nanotechnology tools into their student's lives and educational training. Key to the success of Project NANO are motivated STEM teachers, supportive parents, local businesses and community partners, and engaged higher education faculty who use such tools in basic and applied science applications. The project brings STEM teachers and university faculty together in a new and powerful collaborative.

Teachers use Project NANO scanning electron and optical light microscopes to implement inquiry lesson plans they have developed for their classrooms, which address learning targets and STEM standards. Teacher outcomes measured are rigor of inquiry investigations developed. Preliminary findings have been positive, as teachers are developing more rigorous, standard-based STEM inquiry lesson plans that integrate easily into their current curricula.

Students participating in Project NANO develop a unique and practical understanding of how nanoscale phenomena and concepts are used in variety of fields, which include medicine, chemistry, biology, engineering, environmental science, materials, geology, physics, and astrobiology. Student outcomes measured are student disposition toward science and the effect of STEM tools on student work samples in the areas of rigor and quality. Students are responding by producing higher quality laboratory reports, and they are enjoying the process. Work samples from participating students and 
Oregon's Science Inquiry/Engineering Design Scoring Guide are being used to assess student progress in conducting science inquiry.

Project NANO provides a framework that allows high school and university faculty to work in collaboration to offer students inquiry-based learning experiences comparable to those encountered in college-level laboratory science courses. Shared curriculum, teaching pedagogy, and practical tips enhance the experience for students, teacher cohort veterans, and rookies. We know of no other program across the nation that has brought students a similar combination of sophisticated research grade tools and matching curriculum in their own classroom setting.

Project NANO enables students to experience the nano-world first hand. Students become highly motivated when they can use the SEM to do inquiry-based investigations in a variety of disciplines. The hundreds of digital images that students generate are certain to leave lasting imprints on their education. Eye shadow magnified to $4,800 x$ opens the world of composition of mixtures in a way a label, research paper, or regular light microscope can not. Studying the abdomen of a ladybug magnified to 7,000x, for example, opens the world of structure/function and adaptations so that when a student explores the topic it comes alive. Students learn the power of nanotechnology tools and begin to think about their day-to-day curriculum in a unique way as a result of Project NANO. 